\title{
Rituximab in the treatment of non-Hodgkin's lymphoma
}

\author{
Beate Hauptrock \\ Georg Hess
}

Hematology/Oncology, Johannes Gutenberg-University, Mainz, Germany
Correspondence: Georg Hess

Hematology/Oncology, Johannes

Gutenberg-University, Langenbeckstr.

I, 55I0I Mainz, Germany

Tel +49 6I3। I7 5040

Fax +49 6I3I 17 64II

Email g.hess@3-med.klinik.uni-mainz.de

\begin{abstract}
Besides traditional cytostatic drugs the introduction of monoclonal antibodies has substantially influenced current treatment concepts of non-Hodgkin's lymphoma (NHL). Rituximab, a monoclonal anti-CD20 chimeric antibody, now has been widely evaluated in the various B-cell lymphatic neoplasms. Large phase III studies helped to prove the value of this drug in follicular lymphoma as part of induction or relapse treatment as well as maintenance treatment. The addition of rituximab to the well established CHOP regimens has increased achievable cure rates in diffuse large cell lymphoma, and this combination is now accepted worldwide as standard of care. Although conflicting results are available, rituximab is widely used for the treatment of mantle cell lymphoma. For the less frequent lymphoma entities phase 2 studies show a considerable efficiency for most of these B-NHL variants. Current research focuses on combined chemoimmunotherapy approaches, optimization of dosing regimens, and combination with novel agents.
\end{abstract}

Keywords: non-Hodgkin's lymphoma, rituximab, monoclonal-antibody, targeted therapy

\section{Introduction}

\section{Monoclonal antibodies as targeted therapies}

More than 100 years ago Paul Ehrlich envisioned anti-tumor therapies using monoclonal antibodies (Ehrlich P. 1900. Proc Royal Soc London, 66:424-8.) However, it took several decades to fulfil the technical requirements for the implementation of this immunotherapy approach in clinical practice. Kohler and Milstein developed the hybridoma technique, which enabled large-scale monoclonal antibody production (Kohler and Milstein 1975). Early studies demonstrated efficacy of antibodies and were the basis for the further development of more specific antibodies in non-Hodgkin's lymphoma (NHL) (Nadler et al 1980; Press et al 1987; Maloney et al 1992). With the definition of universal tumor antigens suitable for therapeutic targeting, the generation of highly active drugs was greatly accelerated.

B-lymphocytes are characterized by a variety of specific surface antigens which can serve as specific targets for therapeutic antibodies; however, CD20 early attracted special attention. This antigen is expressed uniformly on all benign or malignant B-cells, except the very early B-cells and mature plasma cells. Therefore, even elimination of all CD20 positive cells allows regeneration of a B-cell repertoire from the pool of immature B-cells and would facilitate sustained production of the acquired immunoglobulin repertoire. The exact function of CD20 is not yet entirely understood. Most probably it is involved in B-cell differentiation and activation, as well as regulation of transmembrane calcium conductance (Riley and Sliwkowski 2000). Importantly, it is expressed stably and not internalized upon specific binding (Smith 2003). Additionally, CD20 is not shed, and there is no soluble form of CD20 that could interfere with therapeutic antibodies. 
Initially, a murine anti-CD20 antibody Y2B8 was developed by BiogenIdec. As murine antibodies are associated with a high rate of development of human antimouse antibodies (HAMA), this could result in allergic reactions and reduced efficacy of the drug. Therefore the primary antibody had been genetically engineered and rituximab is now a chimeric IgG1 antibody with only the antigen binding site originating from the parental murine antibody.

Interestingly, until now there is no full understanding of the precise mechanism of action of this drug. It is generally accepted that effector mechanisms of the host are needed to fully implement therapeutic efficacy. Especially antigen dependent cellular toxicity (ADCC) seems to play an important role, which is promoted by the human Fc portion of the antibody (Clynes et al 2000; Stockmeyer et al 2000; Smith 2003). Polymorphisphms in the Fc-receptor of the effector cells may contribute to the therapeutic efficacy (Cartron et al 2002). Additionally, complement-dependent cytotoxicity (CDC) and direct induction via intracellular signaling are assumed to be involved in tumor cell killing.

Preclinical data showed successful depletion of B-cells from blood and lymph nodes in macaque monkeys. Upon this, the first clinical trial was performed in patients with indolent lymphoma, and rituximab dose was increased up to $500 \mathrm{mg} / \mathrm{m}^{2}$ (Maloney et al 1994). In a subsequent trial in 37 patients using 4 doses of rituximab $375 \mathrm{mg} / \mathrm{m}^{2}$, a response rate of $46 \%$ was noted. These exciting results promoted further development of rituximab.

No dose-limiting toxicity has been determined in these initial trials and, interestingly, no definite maximum tolerable dose or a well established optimal dose of this drug has been found so far. Hence, $375 \mathrm{mg} / \mathrm{m}^{2}$ has become the worldwide accepted rituximab standard dose, at least for nodal NHL. Some studies, however, have tested alternative dose regimens, showing that increased doses might be more efficient (O'Brien et al 2001). Initially, rituximab was given as a once-weekly regimen, but the combination with standard chemotherapy regimens is now usually applied in the rhythm of chemotherapy cycles, although no pharmacokinetic data exist. Recent data suggest that pharmacokinetically based timing might improve efficacy in aggressive lymphoma; however, additional information is required on this and other entities to establish such a concept (Pfreundschuh et al 2007).

The antibody is given over 4 hours as a continuous infusion with incremental application of the drug. Recent trials have shown that an application within one hour might be safely possible as well, and this could further increase the convenience of use (Ghielmini et al 2005b).

The side effect profile of rituximab is well known. Especially during the first application symptoms like fever, chills, and rigors can occur which in general can be terminated by symptomatic treatment with steroids or antihistaminic drugs or lowering of the infusion rate. As these side effects are more common in patients with high tumor load or a high number of circulating tumor cells, an overlap with tumor lysis syndrome can be assumed (Jensen et al 1998; Yang et al 1999). However, side effects are usually less prominent during the subsequent treatment cycles and only sporadically are patients unable to tolerate further rituximab treatment. Additional side effects are rash, nausea and vomiting, headache, or myalgias, but these are usually grade I or II. Specific precautions should be taken in patients prone to viral infections or reactivations, such as those with hepatitis B infection, where fulminant hepatitis cases have been observed (Tsutsumi et al 2005; Aksoy et al 2006; Ozgonenel et al 2006; Perceau et al 2006). The occurrence of cases of leucoencephalopathy upon treatment with rituximab-containing regimens has been alarming, and although their frequency was low these events should be watched carefully (Goldberg et al 2002; Matteucci et al 2002). HAMA are observed with low frequency and their biological meaning remains undetermined. Overall, most studies have shown that the addition of rituximab to various chemotherapy regimens in general contributes only little to the specific toxicity, regardless of whether low- or high-intensity regimens are used. Especially hematopoietic recovery and rate of infections do not seem to be altered (Coiffier et al 2002; Hiddemann et al 2005).

The application of rituximab leads to a depletion of peripheral B-cells and recovery is not noted until 6 months after treatment termination. Initially, potential increase of infection rates during short-term and long-term follow up caused severe concern. But a surprisingly low infection rate has been noted so far, even if long-term maintenance therapy is applied (Ghielmini et al 2005a). However, there are reports of rituximab-associated neutropenia, which can be protracted, and with higher rituximab doses infection rates might increase (Pfreundschuh et al 2007). Only long-term follow up will show if more secondary infections or secondary tumors are diagnosed with several years of continuous B-cell depletion.

The first trials were performed in indolent lymphoma, but rituximab has now been broadly evaluated in almost every sub-entity of NHL. This review will focus on the main 
established indications for rituximab and also include a brief overview of current data in rare lymphoma entities.

\section{Activity in defined lymphoma entities \\ Follicular lymphoma (FL)}

Follicular lymphoma is the most common subtype of indolent NHL, representing about $25 \%$ of all B-NHL and characterized by a heterogeneous clinical course. Frequently, tumors grow slowly and a substantial proportion of patients can be observed for a long period without needing any therapy. Eventually, however, patients develop rapid enlargement of nodes, compression symptoms, or bone marrow insufficiency, and treatment has to be initiated. Until now, no curative treatment besides allogeneic transplantation could be established, and with sufficient follow up almost all patients relapse. Although the disease is susceptible to further treatments, a resistance to conventional cytotoxic drugs can develop during the disease course and hamper further effective treatment. Because of its generally slow progression rate FL was accepted as an ideal disease for the development of rituximab, and the first clinical phase I/II trials of singleagent rituximab were conducted with indolent lymphomas (Maloney et al 1994). As described above, treatment was well tolerated and the dose of $375 \mathrm{mg} / \mathrm{m}^{2}$ for the 4-dose weekly schedule was established.

The pivotal phase II trial tested rituximab monotherapy in refractory or relapsed FL in 166 patients. The overall response rate (ORR) was $48 \%$ with a complete response (CR) rate of $10 \%$. The median time to progression (TTP) reached 11.6 months (McLaughlin et al 1998; Colombat et al 2006). These encouraging results led to the approval of rituximab by the US Food and Drug Administration in 1997. Recently an update of this trial has been published in which an overall best response rate of $74 \%$ was described, with $50 \%$ of patients achieving CR. Median progression-free survival (PFS) was 23.5 months. Interestingly, long-term remissions have been noted in $24 \%$ of patients, who had not relapsed after 5 years. However, as this rate further decreased during follow up, a curative potential at least in a subset of patients cannot be assumed (Colombat et al 2006). Similar data for single-agent rituximab from 185 patients with newly diagnosed or refractory FL was shown by the Swiss Group for Clinical Cancer Research (SAKK) (Ghielmini et al 2004). The ORR was $67 \%$ in chemotherapy-naïve patients and $46 \%$ in pre-treated patients. Previous chemotherapy and bulky disease were identified as independent negative predictors for clinical response.
One of the first studies investigating rituximab monotherapy in untreated follicular lymphoma was published in 2001, showing an ORR of $73 \%$ and a CR of $26 \%$. However, TTP was the same as in the control group of "watch and wait" patients (2 years) (Colombat et al 2001).

To further improve the efficacy of single-agent rituximab via stimulation of the host defence system, the combination of single-agent rituximab with the application of granulocytemacrophage colony-stimulating factor (GM-CSF) has been evaluated. In a recently published phase II study in 33 relapsed patients, an ORR of $70 \%$, a CR (with $\mathrm{CRu}$ [complete remission unconfirmed]) rate of $45 \%$, and a median PFS of 16.5 months (Cartron et al 2008) were noted, which compares favorably with the historic data and merits further evaluation. Other studies analyzed the possibility of re-treating patients in relapse who initially responded to rituximab monotherapy (Davis et al 2000; Lemieux et al 2004; Ghielmini et al 2004b). The response rates were comparable with those of the initial treatment. Surprisingly, median TTP was longer after the rituximab re-treatment than after the previous therapy. It can be speculated that rituximab is associated with a kind of vaccination effect, which can be boosted by subsequent infusions.

From clinical praxis and experience with other tumor entities as well as NHL it is accepted that combination therapies frequently demonstrate a super-additive efficacy of single agents. As additional in vitro analyses demonstrated an additive effect of the combination of rituximab with chemotherapy, combinations of cytotoxic agents with the monoclonal antibody were subsequently evaluated. In untreated patients, Czuczman et al were the first to report on the combination of rituximab with the well established CHOP-regimen (R-CHOP: rituximab, cyclophosphamide, doxorubicin, vincristine, prednisone) in a phase II trial. An ORR of $100 \%$ ( $87 \% \mathrm{CR}$ or $\mathrm{CRu})$ was demonstrated (Czuczman 1999). The data of 9 years of follow up showed that after this period almost $50 \%$ of patients were progression free (Czuczman et al 2004). Median TTP was 82 months. Other examples of an impressive therapeutic efficacy came from trials evaluating, for instance, the combination with fludarabine-based regimens or bendamustine. For example, a multicenter study with 63 patients with relapsed follicular lymphoma or mantle cell lymphoma evaluated the combination of rituximab with bendamustine. The ORR was $90 \%$ with a $60 \%$ CR rate. The median time of PFS was 24 months (Zinzani et al 2004; Rummel et al 2005).

With the availability of the phase II data, a series of large phase III studies was initiated to prove the value of rituximab 
in addition to standard treatments. The trial of the German Low Grade Lymphoma Study Group (GLSG) compared the combination of R-CHOP with CHOP chemotherapy alone (Hiddemann et al 2005). ORRs were similar, but median TTP was significantly reduced in the CHOP arm (2.6 years). In the R-CHOP arm, median TTP was not reached after 3 years of observation. Furthermore, despite the short follow-up time, OS was significantly longer in patients who received R-CHOP. However, the inclusion of consolidation high-dose therapy for a substantial proportion of patients does not allow direct comparison with the below-mentioned trials. The East German Study Group Hematology and Oncology (OSHO) randomized patients with low grade B-NHL to a therapy with MCP (mitoxantrone, chlorambucile, prednisone) vs the combination of R-MCP (Herold et al 2007). The results showed an advantage in response rates (ORR 92\% vs 75\%, CR 50\% vs 25\%) and in median event-free survival (EFS) and PFS (EFS after 47 months: not reached vs 26 months; PFS not reached vs 28.8 months) for patients treated with R-MCP. Four-year OS was significantly increased for patients receiving $\mathrm{R}-\mathrm{MCP}(87 \%$ vs $74 \%$, p = 0.0096). A similar benefit of chemoimmunotherapy was demonstrated in the trial of Marcus et al (2005) comparing R-CVP with CVP (cyclophosphamide, vincristine, prednisone). An update of this trial with a median follow up of 53 months showed a significantly prolonged median TTP (34 months vs 15 months) and OS ( $81 \%$ vs $71 \% ; \mathrm{p}=0.03)$ for patients in the R-CVP group (Marcus et al 2006). In another trial, the impact of rituximab addition to the combination of CHVP (cyclophosphamide, doxorubicin, teniposide, prednisone) plus interferon was analyzed (Salles et al 2004). CR rates were higher in the R-CHVP-interferon arm (75\% vs 59\%) and for a follow up of 5 years there was a statistically significant advantage in EFS (53\% vs 37\%) but not in OS (84\% vs 79\%) for R-CHVP-interferon compared with CHVP-interferon was reported. A significant OS benefit was noted only for patients with high-risk features according to the FLIPI score (Salles et al 2007).

Although the efficacy of the addition of rituximab has been demonstrated for untreated patients, additional randomized phase-III-trials focussed on patients with relapsed disease. The European Organisation for Research and Treatment of Cancer (EORTC) compared CHOP vs R-CHOP and showed a significantly better ORR (85 vs $72 \%$ ) and PFS (33.1 vs 20.2 months) in the R-CHOP arm (van Oers et al 2006). When rituximab was added to the FCM-schedule (fludarabine, cyclophosphamide, mitoxantrone), ORR, PFS, and OS were increased (79 vs 58\%; 3-year PFS not reached vs 21 months; estimated 2-year OS: 90 vs 70\%, NS) (Forstpointner et al 2006). As these studies were started in parallel with first-line trials, a substantial proportion of patients had not been treated with prior rituximab, and a trial including only patients with rituximab pre-treatment has not been performed. Owing to the repeated efficacy of singleagent rituximab and the well balanced characteristics of the various phase III trials, it can be assumed that rituximab is established as a key component of combined chemoimmunotherapy protocols for first- and second-line therapy.

Although the introduction of rituximab has not led to the development of curative treatments, it has markedly prolonged PFS and OS of patients with follicular lymphoma so that many patients ultimately die of other reasons than lymphoma. With this success and the beneficial safety profile, longterm application (maintenance) to prolong the disease free interval has been considered an interesting option. Various maintenance regimens have been tested, from 1 dose every 2 months up to 4 doses every 3 months, which all proved to be feasible and have a remarkably low rate of side effects. Randomized studies investigated the significance of rituximab maintenance therapy after a successful induction therapy. The SAKK randomized untreated and relapsed patients with follicular lymphoma who had at least reached stable disease after a rituximab containing induction between 4 additional rituximab infusions every 8 weeks or no further treatment (Ghielmini et al 2004). Patients receiving rituximab maintenance had an advantage for EFS (23 months vs 12 months). The highest benefit was observed in previously untreated patients. Another trial compared rituximab maintenance therapy in patients initially responding to rituximab with starting the antibody after lymphoma progression (Hainsworth et al 2005). EFS was longer in the group of rituximab maintenance (31.3 months vs 7.4 months). However, duration of the rituximab benefit was similar in the maintenance and the re-treatment group (31.3 months vs 27.4 months), and there was no difference in time to chemotherapy after stopping rituximab. The above-mentioned EORTC trial (van Oers et al 2006) demonstrated a significantly improved PFS and OS for relapsed patients with a rituximab maintenance after $\mathrm{CHOP}$ or R-CHOP therapy. After the results of this trial rituximab was approved for maintenance therapy in patients with relapsed follicular lymphoma (van Oers et al 2006). Similar results in relapsed patients were reported by the GLSG for a rituximab maintenance after R-FCM chemoimmunotherapy (Forstpointner et al 2006).

Whereas maintenance therapy can be considered to be established for patients with relapsed disease, the value of 
maintenance treatment for patients undergoing first-line treatment is being investigated in several trials. The PRIMA trial compares randomly maintenance therapy ( 1 dose, every 3 months, for 2 years) vs no further treatment for patients with chemoimmunotherapy. Furthermore, the next study of the GLSG will evaluate maintenance treatment in the context of high-dose consolidation treatment.

\section{Aggressive lymphoma}

The first phase II trial using rituximab monotherapy in relapsing or refractory patients with diffuse large B-cell lymphoma (DLBCL) was published in 1998 (Coiffier et al 1998). ORR was $37 \%$ and PFS reached 8 months. In spite of this promising single-agent activity, combination therapies rapidly became the focus of interest, and single-agent rituximab is today used only in palliative settings. Several phase II trials demonstrated high and long-lasting remission rates by combining rituximab with chemotherapy in the firstline treatment of patients with aggressive lymphoma. Vose et al (2001) showed that the addition of rituximab to CHOP chemotherapy resulted in an ORR of $89 \%$ with $56 \%$ CR after 6 cycles of this regimen.

Subsequently, randomized phase III trials demonstrated the superiority of the addition of rituximab to CHOP or CHOP-like chemotherapy against CHOP chemotherapy alone. The trial of the French GELA study group (Groupe d'Etudes des Lymphomes de 1'Adulte) comparing 8 cycles R-CHOP with CHOP in elderly patients with DLBCL (Coiffier et al 2002) resulted in a significant survival benefit for patients in the R-CHOP arm (OS 3.1 years vs not reached after 5 years, $\mathrm{p}=0.007$ ). CR rates were $76 \%$ in the $\mathrm{R}-\mathrm{CHOP}$ arm compared with $63 \%$ in the CHOP arm, and EFS was 3.8 years (R-CHOP) vs 1.1 years (CHOP). This benefit was present in patients with low- or high-risk features as determined by the International Prognostic Index (IPI). Initially it was assumed that the bcl-2 status influences treatment results, although this is still under debate (Mounier et al 2003, 2006). This study was path breaking in the approval of the combination of rituximab to chemotherapy for first line treatment. In another trial of elderly patients with aggressive lymphoma, a comparison of CHOP-14 to R-CHOP-14 (RICOVER-60-trial) was carried out (Pfreundschuh et al 2008b). The authors reported a benefit of R-CHOP-14 for PFS and OS. Giving 8 instead of 6 cycles of R-CHOP-14 did not improve the outcome. The results of these trials suggest that at present R-CHOP is the standard first-line treatment for elderly patients with aggressive lymphoma. The results of the GELA-trial could be confirmed by the MInT study (Mabthera
International Trial) for younger patients with low-risk DLBCL receiving CHOP-like chemotherapy (Pfreundschuh et al 2006). Patients in the rituximab combination arm had an increased 3-year EFS (79\% vs 59\%, p < 0.0001) and OS (93\% vs $84 \%, p=0.0001)$. In a recently published followup of the MinT trial (Pfreundschuh et al 2008a) the impact of bulky disease measured by the maximum tumor diameter (MTD) towards the outcome of R-CHOP was analyzed. MTD had an adverse prognostic effect on EFS and OS with increased linearity. Adding rituximab to CHOP decreased, but did not eliminate, this adverse prognostic effect. In the very aggressive B-NHL variants like Burkitt's lymphoma and B-ALL, small trials suggest a beneficial effect of rituximab in these entities, too (Thomas et al 2006).

Ongoing trials in previously untreated patients focus on the comparison of R-CHOP-14 with R-CHOP-21, dose escalation studies with protocols like MegaCHOEP, or the addition of other active drugs, such as those recently reported on the combination of epratuzumab with R-CHOP (Micallef et al 2008).

Despite the advanced outcomes in first line treatment, up to $50 \%$ of patients relapse after standard chemoimmunotherapy, especially if they belong to the high risk population based on IPI (Coiffier 2005). Work is ongoing to establish biological risk markers to identify those patients already early and to optimize first-line treatment. However, for younger patients with relapsed or refractory disease, a salvage therapy followed by high-dose therapy with autologous stem cell transplantation is currently standard of care (Philip et al 1995). Using rituximab for in vivo purging before stem cell apheresis did not alter stem cell mobilization and therefore was rapidly considered as standard of care (Magni et al 2000; Flohr et al 2002). The addition of rituximab to DHAP (dexamethasone, cytarabinoside, cisplatin) salvage chemotherapy was compared with a historical control cohort of patients that received only DHAP (Sieniawski et al 2007). Response rates were higher in the R-DHAP group (63\% vs $42 \%$ ). PFS at 2 years was 57\% with R-DHAP and 18\% with DHAP, and also OS was better in the R-DHAP group (77\% vs 37\%). Kewalramani et al (2004) showed that adding rituximab to ICE (ifosfamide, carboplatin, etoposide) salvage therapy improved CR rates compared with historical control patients only receiving ICE (53\% vs 27\%). PFS was marginally better in patients who underwent transplantation after R-ICE (54\% vs $43 \%$ after 2 years). Another trial to define the role of rituximab in salvage and high-dose therapy compared patients treated with rituximab in combination with DexaBEAM 
Table I Key studies of rituximab in indolent and aggressive non-Hodgkin's lymphoma

\begin{tabular}{|c|c|c|c|c|}
\hline Author & Phase & Regimen & Patients & Results \\
\hline \multicolumn{5}{|c|}{ Indolent lymphoma (follicular lymphoma, single agent) } \\
\hline $\begin{array}{l}\text { Maloney et al } \\
1994\end{array}$ & I & $375 / \mathrm{m}^{2} \times 4$ & 34, pre-treated & ORR: $50 \%$ \\
\hline $\begin{array}{l}\text { McLaughlin et al } \\
1998\end{array}$ & II/III & $375 / \mathrm{m}^{2} \times 4$ & 166, pre-treated & ORR: $48 \%$ med. PFS 9 mo \\
\hline \multicolumn{5}{|c|}{ Indolent lymphoma (follicular lymphoma. combination therapies } \\
\hline $\begin{array}{l}\text { Czuczman 1999; } \\
\text { Czuczman et al } \\
2004\end{array}$ & II & $\mathrm{R}-\mathrm{CHOP} \times 6$ & 38 , naive and pretreated & $\begin{array}{l}\text { ORR: } 100 \% \\
\text { CR: } 58 \% \\
\text { Med. PFS: } 9 \text { y+ }\end{array}$ \\
\hline $\begin{array}{l}\text { Hiddemann et al } \\
2005\end{array}$ & III & $\mathrm{R}-\mathrm{CHOP}$ vs CHOP & 394, naïve & $\begin{array}{l}\text { ORR: } 96 \% \text { vs } 90 \%(p=0.01) \text {; } \\
\text { est. } 2 \text { y OS: } 95 \% \text { vs } 90 \% \\
(p=0.016)\end{array}$ \\
\hline $\begin{array}{l}\text { Herold et al } \\
2007\end{array}$ & III & $\begin{array}{l}\text { R- } \alpha \text { IFN-CHVP } \\
\text { vs } \alpha \text { IFN-CHVP }\end{array}$ & 359, naïve & $\begin{array}{l}\text { ORR } 92 \% \text { (CR } 50 \%) \text { vs ORR } \\
75 \% \text { (CR } 25 \%) \\
\text { PFS at } 47 \text { mo: n.r. vs } 28.8 \text { mo; } \\
4 \text { y OS: } 87 \% \text { vs } 74 \% \\
(p=0.0096)\end{array}$ \\
\hline Salles et al 2007 & III & R-MCP vs MCP & 358, naïve & $\begin{array}{l}\text { CR: } 75 \% \text { vs } 59 \% \text {; } \\
\text { EFS at } 5 \text { y: } 53 \% \text { vs } 37 \% \text {; } \\
\text { OS: } 84 \% \text { vs } 79 \% \text { (n.s.) }\end{array}$ \\
\hline $\begin{array}{l}\text { Marcus et al } \\
2005,2006\end{array}$ & III & R-CVP vs CVP & 321 , naïve & $\begin{array}{l}\text { ORR } 81 \% \text { (CR } 41 \%) \text { vs ORR } \\
57 \% \text { (CR I0\%) } \\
\text { PFS: } 34 \text { vs I5 mo; } 53 \mathrm{mo} ; \\
\text { OS : } 81 \% \text { vs } 71 \%(p=0.03\end{array}$ \\
\hline \multicolumn{5}{|c|}{ Aggressive lymphoma (DLBCL, single agent) } \\
\hline $\begin{array}{l}\text { Coiffier et al } \\
1998\end{array}$ & II & $\mathrm{R} \times 8$ & $30 *$ & ORR: $37 \%$ \\
\hline \multicolumn{5}{|c|}{ Aggressive lymphoma (DLBCL, combination therapies) } \\
\hline $\begin{array}{l}\text { Coiffier et al } \\
2002\end{array}$ & III & $\mathrm{R}-\mathrm{CHOP}$ vs CHOP & 399 & $\begin{array}{l}\text { Med. EFS: } 3.8 \text { y vs I.I y; } \\
\text { Med. OS: n.r. vs } 3.1 \text { y }\end{array}$ \\
\hline $\begin{array}{l}\text { Pfreundschuh } \\
\text { et al } 2006\end{array}$ & III & $\begin{array}{l}\text { R-CHO(E.P } \\
\text { vs CHOP }\end{array}$ & 823 & $\begin{array}{l}\text { Est. } 2 \text { y PFS: } 76 \% \text { vs } 60 \% ; \\
2 \text { y OS: } 94 \% \text { vs } 90 \%\end{array}$ \\
\hline
\end{tabular}

Abbreviations: n.r. not reached; mo, months; y, year; n.s. not significant; CR, complete respones; ORR, overall survival rate; PFS, progress-free survival.

(Dexamethason, BCNU, etoposide, cytarabinoside, melphalan) salvage and with BEAM or TBI/Cy conditioning therapy to a historical control group without rituximab (Hess et al 2006). The OS after 4.5 years in the rituximab group was improved only in patients with aggressive lymphoma (67\% vs 45\%), but not in patients with indolent lymphoma. These studies suggest that patients receiving salvage chemotherapy have a benefit when rituximab is added to chemotherapy. Although randomized trials have not been and probably never will be perfored on this issue, the use of rituximab is generally accepted. To define the optimal salvage regimen, the CORAL study (Collaborative trial in Relapsed Aggressive Lymphoma) randomized relapsed patients between R-ICE and R-DHAP salvage therapy prior to autologous stem cell transplantation (Gisselbrecht et al 2007). Although in an interim analysis high response rates have been reported in this study, patients who were initially exposed to rituximab were more difficult to salvage with the rituximab-containing salvage regimens. The trial is also investigating the role of rituximab maintenance after autologous stem cell transplantation, but results are still outstanding. A recently published Italian randomized 
multicenter trial (Tarella et al 2008) reported on the addition of rituximab to high-dose sequential (HDS) chemotherapy regimen followed by autologous stem cell transplantation. The benefit of rituximab to OS was evident in patients receiving HDS as salvage therapy (64\% with R-HDS vs $38 \%$ with HDS).

The effect of rituximab maintenance after CHOP or R-CHOP therapy was analyzed by Habermann et al (2006). Only patients treated with CHOP, but not with R-CHOP, in first-line therapy had an improved failure-free survival when receiving rituximab maintenance. However, the results of this study must be observed critically because the rituximab dose during the induction therapy was lower than the standard schedule dose (rituximab was added only on cycles 1, 3, 5, and 7). Results of the CORAL trial will help to judge the value of maintenance therapy in aggressive lymphoma.

Rituximab is now an essential element of currently applied first-line and relapse therapies. Studies evaluating dose modification and maintenance therapies are awaited and might expand the current use.

\section{Mantle cell lymphoma (MCL)}

Although initially termed as of intermediate aggressiveness within the Kiel-classification, it has by now become clear that MCL is associated with the poorest prognosis of all peripheral B-cell-lymphoma entities. Single-agent activity of rituximab is limited in this disease. In a trial with 88 patients an ORR of $27 \%$ with only $2.3 \%$ CR was reached and the duration of remission was short (6-12 months) (Ghielmini et al 2005a).

To evaluate the combination of rituximab with chemotherapy in first-line therapy, the GLSG conducted a randomized trial comparing R-CHOP and CHOP in first-line treatment of 122 MCL patients (Lenz et al 2005). The ORR was better in the rituximab arm $(94 \%$ vs $75 \%, \mathrm{p}=0.0054)$ with a clearly superior CR rate (34\% vs 7\%, p = 0.00024). Median time to treatment failure was significantly longer in patients receiving rituximab (21 vs 14 months), but there was no difference in PFS and OS. The efficiency of a combination of FC (fludarabine, cyclophosphamide) with rituximab (R-FC) was analyzed in a randomized British trial (Rule et al 2005). ORR was $93 \%$ in the R-FC and the FC arm and CR rate was similar, too (44\% R-FC vs $40 \%$ FC). There was also no difference in PFS and OS when rituximab was added. By using a combination of rituximab with the intensive chemotherapy regimen hyper-CVAD ( 3 cycles high dose metothrexate and cytarabinoside alternating with 3 cycles cyclophosphamide, vincristine, doxorubicin, and dexamethasone), a longer PFS of $64 \%$ after 3 years was reached (Romaguera et al 2005). ORR was $97 \%$ with a $\mathrm{CR}$ rate of $87 \%$. However, this regimen was accompanied with a high rate of therapy associated mortality (5\%) and cases of MDS and acute leukaemia (4\%). Recently, an OSHO trial failed to demonstrate a benefit for the combination of rituximab with $\mathrm{MCP}$ in comparison with MCP; however, in this trial only a limited patient number with MCL was included.

The GLSG examined the addition of rituximab to a polychemotherapy with FCM (fludarabine, cyclophosphamide, mitoxantrone) in relapsed and refractory MCL in a randomized trial (Forstpointner et al 2004). The results demonstrated an improved ORR in MCL patients in the rituximab arm ( $58 \%$ vs $46 \%$ ), but a low $\mathrm{CR}$ rate ( $13 \%$ vs $0 \%$ ). PFS and OS were prolonged in the R-FCM group (PFS 8 months vs 4 months, OS $65 \%$ vs $35 \%$ after 2 years, $\mathrm{p}=0.01)$.

The influence of rituximab in amelioratin the outcome after autologous stem cell transplantation was examined in a retrospective analysis of Hoerr et al (2004). When rituximab was added to the salvage chemotherapy, a significant benefit in PFS and OS was observed in this study. Another study analyzed the impact of rituximab in conditioning therapy before autologous stem cell transplantation (Dreger et al 2007). Adding rituximab to total body irradiation and cyclophosphamide (TBI/Cy) did not alter engraftment but led to an improved EFS (not reached vs 43 months) and OS ( $87 \%$ vs $77 \%$ after 4 years) compared with a historical control group.

Because duration of MCL remission is frequently short especially in relapsed disease, maintenance therapy has been investigated in a GLSG trial. After the initial randomization to R-FCM vs FCM (Forstpointner et al 2006) a second randomization for rituximab maintenance with 4 doses given after 3 and 9 months was introduced. PFS was 19 months in the observation group and not reached in patients receiving the maintenance therapy after 3 years, suggesting a benefit of rituximab maintenance in MCL patients.

In summary, rituximab is now widely used in MCL therapy, although benefits are not as impressive as in other lymphoma entities and further additional therapeutic options are needed in this disease entity.

\section{Chronic lymphocytic leukemia (CLL) and small lymphocytic lymphoma}

CLL is characterized by the accumulation of a monoclonal population of mature B-cells, resulting in peripheral lymphocytosis, bone marrow failure, lymphadenopathy, and 
splenomegaly. Although some patients experience prolonged phases of stable disease and do not require treatment for a long time, others rapidly progress and subsequently experience poor responses to standard treatment, eg, chlorambucileand fludarabine-based therapies. Monoclonal antibodies are attractive for these patients and have been evaluated in various trials (Table 2). However, in CLL, CD20 is expressed to a lesser extent than in normal B-cells or other B-NHL and, furthermore, soluble CD20 may hamper the efficacy of rituximab. In fact, initial results of standard single-agent treatment in relapsed disease were disappointing. Trials using standard $375 \mathrm{mg} / \mathrm{m}^{2}$ rituximab dosing showed response rates between 0\% and 25\% (McLaughlin et al 1998; Huhn et al 2001; O'Brien et al 2001). There were improved responses with increased doses of rituximab of up to $2250 \mathrm{mg} / \mathrm{m}^{2}$ which resulted in response rates of $75 \%$ or a dose-intensive rituximab schedule $\left(375 \mathrm{~g} / \mathrm{m}^{2} \times 3 /\right.$ weekly, for 4 weeks $)$ resulting in a response rate of $45 \%(3 \% \mathrm{CR})$ (Byrd et al 2001). In a first-line trial, treatment with the monoclonal antibody for 4 cycles every 6 months for up to 2 years gave a $58 \%$ rate $(9 \%$ CR) (Hainsworth et al 2003). However, these results did not translate into clinical praxis. In contrast, combination therapy with fludarabine-based regimens in relapsed disease and first line therapy gave surprisingly good results and hopefully can be confirmed in additional trials
(Keating et al 2005; Wierda et al 2005). For example, in relapsed disease, in 177 patients FCR (fludarabine, cyclophosphamide, rituximab) resulted in a CR in $25 \%$ of patients, a nodular PR in $16 \%$, and PR in $32 \%$ of patients for an ORR of $73 \%$, an outcome that has never been achieved with other treatments. The trial testing FCR in untreated patients has recently been updated (Tam et al 2008). At median follow up of 6 years, in 300 patients the ORR was 95\% and $72 \%$ achieved a CR. 6y-PFS and OS were $51 \%$ and $77 \%$ and median time to progression was 80 months. Although patient selection seemed favorable in this trial, the initial results of combined modality treatment stimulated a randomized study of the German CLL study group comparing FC with FC-R in patients with untreated CLL requiring treatment (CLL 8). The accrual of the trial closed in 2007, and first results are expected at the end of this year. As there is evidence of synergistic efficacy of nucleoside analogues and rituximab besides the predominantly used fludarabine based regimes, other combination therapies were evaluated. The combination of cladribine with rituximab with or without additional cyclophosphamid resulted in an ORR of $67 \%-78 \%$ in heavily pre-treated patients (Robak et al 2007). Finally, pentostatin, cyclophosphamide, and rituximab were tested as an alternative combination in untreated patients with CLL. In 65 patients an ORR of $91 \%$ could be achieved ( $41 \% \mathrm{CR})$

Table 2 Key studies of rituximab in chronic lymphocytic leukemia and SLL

\begin{tabular}{|c|c|c|c|c|}
\hline Autor & Phase & Regimen & Patients & Results \\
\hline \multicolumn{5}{|c|}{ Single-agent rituximab } \\
\hline $\begin{array}{l}\text { McLaughlin et al } \\
1998\end{array}$ & $\mathrm{I} / \mathrm{II}$ & $375 / \mathrm{m}^{2} \times 4$ & 30 , pre-treated & ORR: I3\%, PFS n.a. \\
\hline Byrd et al 2001 & II & $\begin{array}{l}375 / \mathrm{m}^{2} \times 3 \text { weekly } \\
\text { for } 4 \text { weeks, rep. every } \\
6 \text { mo }\end{array}$ & 33 relapsed & $\begin{array}{l}\text { ORR: } 45 \% \text { med. PFS } \\
10 \text { mo. }\end{array}$ \\
\hline $\begin{array}{l}\text { O'Brien et al } \\
200 \text { I }\end{array}$ & II & $375-2250 / \mathrm{m}^{2}$ & $\begin{array}{l}8\left(\text { at } 2250 \mathrm{mg} / \mathrm{m}^{2}\right), \\
\text { relapsed }\end{array}$ & ORR: $75 \%$ \\
\hline $\begin{array}{l}\text { Hainsworth et al } \\
2003\end{array}$ & II & $375 / \mathrm{m}^{2}$ & 44 untreated & $\begin{array}{l}\text { ORR } 51 \% \text {, CR } 4 \% \text {, med. } \\
\text { PFS } 19 \text { months }\end{array}$ \\
\hline \multicolumn{5}{|c|}{ Combination therapies } \\
\hline $\begin{array}{l}\text { Wierda et al } \\
2005\end{array}$ & II & FCR & I 77 relapsed & $\begin{array}{l}\text { ORR } 73 \% \text {, CR 25\%; med. } \\
\text { PFS } 28 \text { mo, }\end{array}$ \\
\hline $\begin{array}{l}\text { Robak et al } \\
2007\end{array}$ & II & 2-CDA, R, \pm Cyclo & 46 relapsed & $\begin{array}{l}\text { ORR } 74 \% \text {, med. PFS } \\
12 \mathrm{mo}\end{array}$ \\
\hline $\begin{array}{l}\text { Keating et al } \\
2005 ; \text { Tam et al } \\
2008\end{array}$ & II & FCR & 300 untreated & $\begin{array}{l}\text { ORR: } 95 \%, 72 \% \text { med. } \\
\text { PFS } 80 \text { mo }\end{array}$ \\
\hline Kay et al 2007 & II & Pentostatin, Cylo, R & 64 untreated & $\begin{array}{l}\text { ORR } 91 \% \text {, CR } 41 \% \text {, med. } \\
\text { PFS } 33 \text { mo }\end{array}$ \\
\hline
\end{tabular}

Abbreviations: n.a. not applicable/available; mo, months;y,year; n.s. not significant; R, rituximab; Cyclo, cyclophosphamide; 2-CDA, cladribine; FCR, fludarabine, cyclophosphamide, rituximab; CR, complete response; ORR, overall survival rate; PFS, progress-free survival. 
(Kay et al 2007), with all precautions in the comparison of phase II data; however, median PFS was shorter (33 months) compared with FCR. In summary, the nucleoside analogues in combination with rituximab appear to be highly efficacious for the treatment of CLL. It can be speculated, from published data and with the availability of presumably positive data from the CLL 8 trial, that rituximab will be approved as a standard component of CLL treatment.

\section{HIV-associated NHL}

Highly active anti-retroviral therapy has led to improved survival of patients with HIV infections. NHLs, mainly the aggressive variants, have now evolved into one of the most common malignancies in these patients. Due to the severe immunosuppression, patients initially were precluded from treatment with rituximab-containing regimens. However, as lymphoma-specific prognosis of these patients is inferior to that of non-HIV positive patients, a separate evaluation of the benefits of monoclonal antibody treatment was initiated. First trials showed promising response rates with the addition of rituximab (Boue et al 2006), but a randomized phase III trial showed conflicting results (Kaplan et al 2005). A superior ORR for R-CHOP compared with CHOP was noted ( 57.6 vs $47 \%$ ) but there was no OS benefit, as a higher treatment-related mortality was observed (14\% vs $2 \%$ ). For daily praxis, individual decision making should be considered, where immune status, performance status, preexisting infections, and the lymphoma specific risk should be taken into account (Sparano 2007). A consequent antibiotic co-treatment and the use of growth factors seem advisable (Mounier et al 2007).

\section{Post-transplantation lymphoproliferative disorders (PTLD)}

PTLD can occur in patients after solid-organ or stem cell transplantation with a high incidence (Leonard et al 2003). PTLD is mostly of B-cell origin, associated with EBV infection or reactivation, and features characteristics of aggressive lymphoma with rapid disease course and involvement of atypical sites. Tapering of immunosuppression and chemotherapy have been widely used, with mixed responses, high relapse rates and, in the latter case, high treatment-associated mortality (Leonard et al 2004). Early retrospective analyses evaluating single-agent rituximab gave variable results, with response rates from $20 \%$ to $100 \%$ (Benkerrou et al 1998; Choquet et al 2006). In a prospective multicenter phase II trial in 46 patients with PTLD after solid organ transplantation, patients received 4-weekly infusion of rituximab. In 43 evaluable patients the ORR was 44\%, and remissions were sustained for 1 year in $68 \%$ of responders. OS for the entire cohort was $67 \%$ at 1 year (Choquet et al 2006). As median PFS was 6 months in another trial including 60 patients (Choquet et al 2007), efforts are made to fully explore the efficacy of rituximab in combination therapies for PTLD. In conclusion, rituximab is a rational choice for patients with this difficult disease, but may not be sufficient as single-agent treatment if patients have high-risk features.

\section{Other lymphoma entities}

\section{Marginal zone lymphoma (MZL)}

MZL accounts for approximately $8 \%-12 \%$ of all NHL and comprises 3 related subtypes with distinct biological features and clinical characteristics. Extranodal MZLs (MALT) are distinguished from nodal MZL and splenic MZL. All subtypes arise from B-cells that have undergone post-follicular differentiation, in the context of chronic antigenic stimulation such as auto-immune mechanisms or chronic infection. Whereas nodal MZL are frequently treated in similarly to other indolent entities, extranodal and splenic marginal zone lymphoma are examined differently.

\section{Extranodal MZL}

These lymphomas usually arise in various extranodal sites such as conjunctive, stomach, salivary glands, and many others. They are characterized by an indolent disease course and a slow dissemination rate, and are associated with a good prognosis.

The most frequent subtype is gastric MZL, which frequently occurs in the context of chronic Heliobacter pylori infection (Wotherspoon et al 1991). Forty percent of gastric MZL are of indolent, whereas $60 \%$ are of aggressive histology, and the latter are frequently diagnosed as diffuse large cell lymphomas. In case of indolent characteristics associated with $H$. pylori infection, eradication can lead to resolution of the disease (Wotherspoon et al 1991), whereas patients experiencing relapse upon this treatment and progressive patients require systemic treatment (Morgner et al 2007). Whereas patients with aggressive NHL are in general treated with R-CHOP, the significance of rituximab in indolent disease has not been extensively studied. Single-agent treatment for 4 weeks resulted in an ORR of $64 \%$ and a CR rate of $29 \%$ in gastric lymphoma in a phase II study in 35 patients with extranodal MZL. In a study focusing on primary gastric lymphoma, 26 patients showed an ORR of 77\% (CR 46\%), and with a median follow up of 33 months only 2 patients had experienced relapse (Martinelli et al 2005). In small series, 
patients with ocular MZL have been treated with considerable success, but systematic evaluation is necessary (Nuckel et al 2004; Zinzani et al 2005).

Localized extranodal MZL outside the stomach can sometimes be treated with curative intent by radiation therapy; however, other patients experience extensive disease and require systemic treatment, for which various agents are used. In this context, single-agent rituximab resulted in an ORR of $80 \%$ in patients with no initial gastric involvement and a median response duration of 10.5 months (Conconi et al 2003). Studies evaluating combined modality treatment are under way.

\section{Splenic marginal zone lymphoma (SMZL)}

SZML has been accepted recently as a separate entity (Harris et al 1994). It features distinct clinical signs such as predominant splenomegaly, lymphocytosis, and cytopenias. In contrast, lymphadenopathy is infrequently found on initial diagnosis. Some cases seem to be associated with hepatitis C virus infection (Mele et al 2003) and frequently autoimmune phenomena are found, which are often the main reason for treatment initiation. Most of the patients are treated with splenectomy and can experience long-term remissions (Thieblemont et al 2002; Thieblemont et al 2003). Data supporting a potential effect of rituximab are still scarce, except for anecdotical reports. A small study evaluated the value of first-line rituximab treatment in 16 patients. In all patients normalization of spleen size was noted and the ORR was $100 \%$, with a CR of $69 \%$, and prolonged remissions were noted in some patients (Kalpadakis et al 2007).

With these limited data, rituximab could be considered as a therapeutic alternative in patients intolerant to splenectomy or chemotherapy on the basis of an individual treatment decision.

\section{Hairy cell leukemia (HCL)}

HCL is assigned to indolent NHL and is clinically characterized by splenomegaly associated with pancytopenia. Diagnosis is made upon distinct cytological and immunophenotypic findings. Patients may experience a disease course without requiring treatment, but most of the patients suffer from infections and progression of splenomegaly so that treatment has to be initiated.

Interferon-alpha, pentostatin, and cladribine have been introduced consecutively in the treatment of HCL, and the last named is now accepted as the standard of care (Golomb et al 1987; Spiers et al 1987; Piro et al 1990; Grever et al 1995; Rai et al 1995). However, almost all patients harbor minimal residual disease and eventually relapse after treatment (Pileri et al 1994). In these, rituximab has been evaluated in small series, which gave heterogeneous results. A trial in 15 patients with relapsed disease resulted in an ORR of $80 \%$ and a CR of $53 \%$, in marked contrast to another series of 24 patients in which only $26 \%$ of patients responded (Nieva et al 2003; Thomas et al 2003). Elimination of minimal residual disease after treatment with nucleoside analogues could be achieved with rituximab (Ravandi et al 2006), and current recommendations suggest using the antibody in case of cladribine and pentostatine failure (Lauria et al 2001; Golomb 2008).

\section{Waldenström's disease (WM)}

WM is a distinct clinicopathological entity whose diagnostic criteria include presence of monoclonal IgM, bone marrow infiltration with small lymphocytes with plasmacytoid/ plasma cell differentiation, and an intertrabecular infiltration pattern (Owen et al 2003). Frequently symptoms such as fatigue, neuropathy, amyloid associated cardiomyopathy, or cytopenias due to bone marrow involvement are present during the disease course. Owing to the limited number of patients there are only few clinical trials, and results of studies in other lymphoma entities have been extrapolated for therapeutic decision making. Because all WM cells eventually express CD20, rituximab was explored and initial trials showed some efficacy of the drug. Treon et al (2001) evaluated the single-agent activity in a series of 30 patients with relapsed disease, and with the criteria used in this trial an ORR of $60 \%$ was noted. Additional trials showed response rates of $44 \%$ and $52 \%$ (24.6\% minor responses) (Dimopoulos et al 2002; Gertz et al 2004). Interestingly, a protracted response to rituximab was noted in a large proportion of responding patients (Treon et al 2005). In some patients a paradoxical raise of IgM can be observed with initial rituximab treatment (flare), which can result in the development of hyper-viscosity syndrome. Rituximab has now become one of the primary single-agent choices for first-line treatment of WM. Combination with chemotherapy was evaluated in small studies, and recently the results of a prospective phase II trial evaluating the combination of dexamethasone, cyclophosphamide, and rituximab in previously untreated patients were reported. Seventy-two patients were enrolled and $74 \%$ of them achieved CR or PR. Twoyear PFS was $67 \%$, and was $80 \%$ in responding patients (Dimopoulos et al 2007). Furthermore, in the subgroup of patients enrolled in the study of the GLSG, patients randomized to R-CHOP experienced a higher response rate 
than patients treated with $\mathrm{CHOP}$, which was translated into a significant prolongation of PFS (Buske et al in press). Rituximab could be established as an active treatment for this disease entity.

\section{Lymphoma of the central nervous system (CNS-lymphoma)}

The treatment of primary CNS-lymphoma, almost uniformly of aggressive B-cell subtype, is still one of the major challenges in NHL. Whereas methotrexate is accepted as the therapeutic mainstay for first-line treatment (Ferreri et al 2003), curing relapsed disease is almost impossible. Although rituximab does not cross the blood-brain barrier physiologically, in neoplastic processes within the CNS the barrier might become permeable for monoclonal antibodies (Wong 2005). Therefore, rituximab could be a reasonable candidate drug to improve treatment results, and various therapeutic approaches have been evaluated. A small initial series reported on 3 out of 4 patients with primary CNS-lymphoma responding to intrathecal rituximab treatment (Schulz et al 2004). A phase I trial in patients with lymphomatous meningitis reported on 6 out of 10 patients with cytological responses and reduction of tumor masses in 3 patients (Rubenstein et al 2007). However, survival of patients was poor. The combination of rituximab with temozolomide has attracted some attention in CNS-lymphoma treatment. In a small series of patients an ORR of $100 \%$ was observed. However, in a recently reported trial median PFS did not differ from single temozolomide treatment and an ORR of 53\% was observed (Enting et al 2004). In a retrospective study an ORR of $100 \%$ was reported for the combination of rituximab with a methotrexate based regimen (R-MTX) (Yamanaka et al 2008), but this approach requires additional supporting data. A recently published prospective trial reported on a combined modality treatment strategy including methotrexate-based chemotherapy (MVP), rituximab, and whole-brain irradiation and consolidation treatment with cytarabinoside in 30 untreated CNS-NHL patients (Shah et al 2007). An ORR of $93 \%$ to 5 cycles of R-MVP was observed. CR-rate was $44 \%$ at this time point and further improved after completing the entire treatment, and 2-year PFS was 57\%. The benefit of rituximab cannot easily be denominated in this treatment approach. However, CSF rituximab levels were $0.1 \%-4.4 \%$ of serum levels and therefore at least some activity can be assumed. Although these are stimulating data, in conclusion, no defined role of rituximab as single agent or as part of combination therapy for patients with primary CNS-lymphoma has been established at this stage and further clinical work is needed.

\section{Multiple myeloma (MM)}

Newer findings have refuted the initially accepted CD20 negativity of plasma cells (Gorschluter et al 2001). In a small proportion of patients with MM, CD20 positive plasma cells have been found; however, the expression pattern is frequently not uniform. In addition, CD20 expression may change during the disease course (Robillard et al 2003; Bergua et al 2008), and it may be worthwhile occasionally repeating diagnostic evaluation. The dual compartment theory of MM assumes that two different cell populations are present: besides the classical, terminally differentiated MM plasma cell, a smaller CD20 positive B-cell population is postulated, which is clonogenic and might be responsible for myeloma initiation, progression, and maintenance (Chen and Epstein 1996; Rottenburger et al 1999; Pilarski et al 2000; Matsui et al 2004). If this is true, elimination of the precursor cell could prevent relapse after treatment for MM. Although the dual compartment theory is not generally accepted, clinical trials exploring rituximab have been initiated. In small series, various responses have been observed in selected patients. Partial remissions are rare; however, a stabilization of paraprotein levels has been observed in $50 \%-57 \%$ of patients for a period of up to 27 months (Treon et al 2002; Moreau et al 2007). So, although there is not yet a clearly established role of rituximab in the treatment of $\mathrm{MM}$, future trials may help to elucidate its potential in this disease.

\section{Summary and perspective}

The introduction of rituximab for the treatment of NHL has been a milestone for patients affected with these diseases. A positive influence on results could be achieved in almost any randomized clinical trial, and even in population-based registries a lowering of lymphoma specific mortality could be noted. Therefore it can be concluded that rituximab, with only few exceptions, can today be generally accepted as a standard component of anti B-NHL therapies. Moreover, the successful implementation of an immunotherapy approach has triggered the development of a variety of other monoclonal antibodies in lymphoma and unrelated tumor entities, and has at last helped to bring Paul Ehrlich's vision to fruition.

Today, monotherapy, combination chemoimmunotherapy, and maintenance strategies have been successfully used in large trials, especially of diffuse large B-cell lymphoma, follicular lymphoma, and mantle cell lymphoma, where rituximab now is one of the key drugs for the treatment of these diseases. In rarer lymphoma entities only few randomized trials are available, but from these and from phase II trials 
the use of the drug seems reasonable in MZL, WM, HCL, HIV-associated lymphomas with special precautions, and recently CLL. The role of rituximab in the treatment of MM remains to be answered. Although this rapidly driven development has addressed so many subtypes of NHL, until now knowledge about optimal dosing and application schedules is still surprisingly scarce.

There are several other antibodies for the treatment of malignant lymphoma which are already established or in clinical development. Alemtuzumab, an anti-CD52 antibody, has been approved for the treatment of CLL, and radioimmunoconjugates targeting CD20 are in use for patients with follicular and transformed lymphoma and also for other lymphoma subtypes. Several other CD20 antibodies are in clinical trials, and ofatumomab, especially, could be available shortly. Antibodies targeting CD19, CD20, CD22, in combination with a toxin, CD23, CD40, CD80, and HLA-DR are being evaluated in clinical trials, and their additional benefit will be evaluated in coming years (DiJoseph et al 2004, 2006; Byrd et al 2005; Czuczman et al 2005; Foreno-Torres et al 2006). Although it seems unlikely now that these drugs will add as much benefit as rituximab, they may help to further improve patient prognosis.

A variety of other new agents, eg, proteosome inhibitors, inhibitors of the mammalian target of rapamycine, histone deacytlase inhibitors, BH3 mimetics and many more, which will be of interest to evaluate for their potential to further improve the efficacy of immunochemotherapy regimens. Current research focuses on the preclinical evaluation of potential partners for these kinds of therapeutic agents, and first clinical trials are promising.

A systematic evaluation of all these newer agents, together with established agents such as cytotoxic agents and rituximab, is indispensable to fully elucidate their potential and to guide the next generation of therapeutic combinations.

\section{Acknowledgment}

The authors would like to thank S. Möller and I. Schmidt for their help in preparation of the manuscript.

\section{Disclosures}

Dr Hess has received a speaker's honorarium from Roche.

\section{References}

Aksoy S, Abali H, Kilickap S, Erman M, et al. 2006. Accelerated hepatitis $\mathrm{C}$ virus replication with rituximab treatment in a non-Hodgkin's lymphoma patient. Clin Lab Haematol, 28:211-4.

Benkerrou M, Jais JP, Leblond V, et al. 1998. Anti-B-cell monoclonal antibody treatment of severe posttransplant B-lymphoproliferative disorder: prognostic factors and long-term outcome. Blood, 92:3137-47.
Bergua JM, Cabrera C, Arteta EG, et al. 2008. Rituximab in CD20 positive multiple myeloma. Leukemia, 22:1082-3.

Boue F, Gabarre J, Gisselbrecht C, et al. 2006. Phase II trial of CHOP plus rituximab in patients with HIV-associated non-Hodgkin's lymphoma. J Clin Oncol, 24:4123-8.

Buske C, Hoster E, Dreyling M, et al. The addition of rituximab to front-line therapy with CHOP (R-CHOP) results in a higher response rate and longer time to treatment failure in patients with lymphoplasmacytic lymphoma - results of a randomized trial of the German Low Grade Lymphoma Study Group (GLSG). Leukemia, In press.

Byrd JC, Murphy T, Howard RS, et al. 2001. Rituximab using a thrice weekly dosing schedule in B-cell chronic lymphocytic leukemia and small lymphocytic lymphoma demonstrates clinical activity and acceptable toxicity. J Clin Oncol, 19:2153-64.

Cartron G, Zhao-Yang L, Baudard M, et al. 2008. Granulocyte-macrophage colony-stimulating factor potentiates rituximab in patients with relapsed follicular lymphoma: results of a phase II study. J Clin Oncol, 26:2725-31

Cartron G, Dacheux L, Salles G, et al. 2002. Therapeutic activity of humanized anti-CD20 monoclonal antibody and polymorphism in IgG Fc receptor Fcgamma RIIIa gene. Blood, 99:754-8.

Chen BJ, Epstein J. 1996. Circulating clonal lymphocytes in myeloma constitute a minor subpopulation of B cells. Blood, 87:1972-6.

Choquet S, Oertel S, Leblond V, et al. 2007. Rituximab in the management of post-transplantation lymphoproliferative disorder after solid organ transplantation: proceed with caution. Ann Hematol, 86:599-607.

Choquet S, Leblond V, Herbrecht R, et al. 2006a. Efficacy and safety of rituximab in B-cell post-transplantation lymphoproliferative disorders: results of a prospective multicenter phase 2 study. Blood, 107:3053-7.

Clynes RA, Towers TL, Presta LG, et al. 2000. Inhibitory Fc receptors modulate in vivo cytoxicity against tumor targets. Nat Med, 6:443-6.

Coiffier B. 2005. State-of-the-art therapeutics: diffuse large B-cell lymphoma. J Clin Oncol, 23:6387-93.

Coiffier B, Haioun C, KettererN, et al. 1998. Rituximab (anti-CD20 monoclonal antibody) for the treatment of patients with relapsing or refractory aggressive lymphoma: a multicenter phase II study. Blood, 92:1927-32.

Coiffier B, Lepage E, Briere J, et al. 2002. CHOP chemotherapy plus rituximab compared with $\mathrm{CHOP}$ alone in elderly patients with diffuse large-B-cell lymphoma. $N$ Engl J Med, 346:235-42.

Colombat P, Brousse N, Morschhauser F, et al. 2006. Single treatment with rituximab monotherapy for low-tumor burden follicular lymphoma (FL): survival analyses with extended follow-up of 7 years. ASH Annual Meeting Abstracts, 108:486.

Colombat P, Salles G, Brousse N, et al. 2001. Rituximab (anti-CD20 monoclonal antibody) as single first-line therapy for patients with follicular lymphoma with a low tumor burden: clinical and molecular evaluation. Blood, 97:101-6.

Conconi A, Martinelli G, Thieblemont C, et al. 2003. Clinical activity of rituximab in extranodal marginal zone B-cell lymphoma of MALT type. Blood, 102:2741-5.

Czuczman M. 1999. CHOP plus rituximab chemoimmunotherapy of indolent B-cell lymphoma. Semin Oncol, 26:88-96.

Czuczman MS, Thall A, Witzig TE, et al. 2005. Phase I/II study of galiximab, an anti-CD80 antibody, for relapsed or refractory follicular lymphoma. J Clin Oncol, 23:4390-8.

Czuczman MS, Weaver R, Alkuzweny B, et al. 2004. Prolonged clinical and molecular remission in patients with low-grade or follicular nonHodgkin's lymphoma treated with rituximab plus CHOP chemotherapy: 9-year follow-up. J Clin Oncol, 22:4711-6.

Davis TA, Grillo-Lopez AJ, White CA, et al. 2000. Rituximab anti-CD20 monoclonal antibody therapy in non-Hodgkin's lymphoma: safety and efficacy of re-treatment. $J$ Clin Oncol, 18:3135-43.

DiJoseph JF, Goad ME, Dougher MM, et al. 2004. Potent and specific antitumor efficacy of CMC-544, a CD22-targeted immunoconjugate of calicheamicin, against systemically disseminated B-cell lymphoma. Clin Cancer Res, 10:8620-9. 
DiJoseph JF, Dougher MM, Kalyandrug LB, et al. 2006. Antitumor efficacy of a combination of CMC-544 (inotuzumab ozogamicin), a CD22-targeted cytotoxic Immunoconjugate of calicheamicin, and rituximab against non-Hodgkin's B-cell lymphoma. Clin Cancer Res, 12:242-9.

Dimopoulos MA, Zervas C, Zomas A, et al. 2002. Treatment of Waldenstrom's macroglobulinemia with rituximab. J Clin Oncol, 20, 2327-33.

Dimopoulos MA, Anagnostopoulos A, Kyrtsonis MC, et al. 2007. Primary treatment of Waldenstrom macroglobulinemia with dexamethasone, rituximab, and cyclophosphamide. J Clin Oncol, 25:3344-9.

Dreger P, Rieger M, Seyfarth B, et al. 2007. Rituximab-augmented myeloablation for first-line autologous stem cell transplantation for mantle cell lymphoma: effects on molecular response and clinical outcome. Haematologica, 92:42-9.

Enting RH, Demopoulos A, DeAngelis LM, et al. 2004. Salvage therapy for primary CNS lymphoma with a combination of rituximab and temozolomide. Neurology, 63:901-3.

Ferreri AJ, Abrey LE, Blay JY, et al. 2003. Summary statement on primary central nervous system lymphomas from the Eighth International Conference on Malignant Lymphoma, Lugano, Switzerland, June 12 to 15, 2002. J Clin Oncol, 21:2407-14.

Flohr T, Hess G, Kolbe K, et al. 2002. Rituximab in vivo purging is safe and effective in combination with CD34-positive selected autologous stem cell transplantation for salvage therapy in B-NHL. Bone Marrow Transplant, 29:769-75.

Foreno-Torres A, Furman RR, Rosenblatt JD. 2006. A humanized antibody against CD40 (SGN-40) is well tolerated and active in non-Hodgkin's lymphoma (NHL): results of a phase I study, p. 7534.

Forstpointner R, Dreyling M, Repp R, et al. 2004. The addition of rituximab to a combination of fludarabine, cyclophosphamide, mitoxantrone (FCM) significantly increases the response rate and prolongs survival as compared with FCM alone in patients with relapsed and refractory follicular and mantle cell lymphomas: results of a prospective randomized study of the German Low-Grade Lymphoma Study Group. Blood, 104:3064-71.

Forstpointner R, Unterhalt M, DreylingM, et al. 2006. Maintenance therapy with rituximab leads to a significant prolongation of response duration after salvage therapy with a combination of rituximab, fludarabine, cyclophosphamide, and mitoxantrone (R-FCM) in patients with recurring and refractory follicular and mantle cell lymphomas: Results of a prospective randomized study of the German Low Grade Lymphoma Study Group (GLSG). Blood, 108:4003-8.

Gertz MA, Rue M, Blood E, et al. 2004. Multicenter phase 2 trial of rituximab for Waldenstrom macroglobulinemia (WM): an Eastern Cooperative Oncology Group Study (E3A98). Leuk Lymphoma, 45:2047-55.

Ghielmini M, Schmitz SF, Cogliatti S, et al. 2005a. Effect of single-agent rituximab given at the standard schedule or as prolonged treatment in patients with mantle cell lymphoma: a study of the Swiss Group for Clinical Cancer Research (SAKK). J Clin Oncol, 23:705-11.

Ghielmini M, Schmitz SF, Cogliatti SB, et al. 2004. Prolonged treatment with rituximab in patients with follicular lymphoma significantly increases event-free survival and response duration compared with the standard weekly x 4 schedule. Blood, 103, 4416-23.

Ghielmini M, Negretti L, Lerch E, et al. 2005b. Infusion speed-escalation trial to give full-dose rituximab in one hour without steroids pre-medication. ASH Annual Meeting Abstracts, 106:2451.

Gisselbrecht C, Schmitz N, Mounier N, et al. 2007. R-ICE versus R-DHAP in relapsed patients with CD20 diffuse large B-cell lymphoma (DLBCL) followed by stem cell transplantation and maintenance treatment with rituximab or not: first interim analysis on 200 patients. CORAL Study. ASH Annual Meeting Abstracts, 110:517.

Goldberg SL, Pecora AL, Alter RS, et al. 2002. Unusual viral infections (progressive multifocal leukoencephalopathy and cytomegalovirus disease) after high-dose chemotherapy with autologous blood stem cell rescue and peritransplantation rituximab. Blood, 99:1486-8.
Golomb HM, Fefer A, Golde DW, et al. 1987. Sequential evaluation of alpha-2b-interferon treatment in 128 patients with hairy cell leukemia. Semin Oncol, 14:13-7.

Golomb HM. 2008. Hairy cell leukemia: treatment successes in the past 25 years. $J$ C Oncol, 26:2607-9.

Gorschluter M, Ziske C, Glasmacher A, et al. 2001. Current clinical and laboratory strategies to augment the efficacy of immunotherapy in multiple myeloma. Clin Cancer Res, 7:2195-204.

Grever M, Kopecky K, Foucar MK, et al. 1995. Randomized comparison of pentostatin versus interferon alfa-2a in previously untreated patients with hairy cell leukemia: an intergroup study. J Clin Oncol, 13:974-82.

Habermann TM, Weller EA, Morrison VA, et al. 2006. Rituximab-CHOP versus $\mathrm{CHOP}$ alone or with maintenance rituximab in older patients with diffuse large B-cell lymphoma. J Clin Oncol, 24:3121-7.

Hainsworth JD, Litchy S, Shaffer DW, et al. 2005. Maximizing therapeutic benefit of rituximab: maintenance therapy versus re-treatment at progression in patients with indolent non-Hodgkin's lymphoma - randomized phase II trial of the Minnie Pearl Cancer Research Network. J Clin Oncol, 23:1088-95.

Hainsworth JD, Litchy S, Barton JH, et al. 2003. Single-agent rituximab as first-line and maintenance treatment for patients with chronic lymphocytic leukemia or small lymphocytic lymphoma: a phase II trial of the Minnie Pearl Cancer Research Network. J Clin Oncol, 21:1746-51.

Harris NL, Jaffe ES, Stein H, et al. 1994. A revised European-American classification of lymphoid neoplasms: a proposal from the International Lymphoma Study Group. Blood, 84:1361-92.

Herold M, Haas A, Srock S, et al. 2007. Rituximab added to first-line mitoxantrone, chlorambucil, and prednisolone chemotherapy followed by interferon maintenance prolongs survival in patients with advanced follicular lymphoma: An East German Study Group Hematology and Oncology Study. J Clin Oncol, 25:1986-92.

Hess G, Flohr T, Kolbe K, et al. 2006. Effect of rituximab on the long-term outcome after high-dose therapy for relapsed B-cell non-Hodgkin's lymphoma. Ann Hematol, 85:769-79.

Hiddemann W, Kneba M, Dreyling M, et al. 2005. Frontline therapy with rituximab added to the combination of cyclophosphamide, doxorubicin, vincristine, and prednisone (CHOP) significantly improves the outcome for patients with advanced-stage follicular lymphoma compared with therapy with $\mathrm{CHOP}$ alone: results of a prospective randomized study of the German Low-Grade Lymphoma Study Group. Blood, 106:3725-32.

Hoerr AL, Gao F, Hidalgo J, et al. 2004. Effects of pretransplantation treatment with rituximab on outcomes of autologous stem-cell transplantation for non-Hodgkin's lymphoma. J Clin Oncol, 22:4561-6.

Huhn D, von Schilling C, Wilhelm M, et al. 2001. Rituximab therapy of patients with B-cell chronic lymphocytic leukemia. Blood, 98:1326-31

Jensen M, Winkler U, Manzke O, et al. 1998. Rapid tumor lysis in a patient with B-cell chronic lymphocytic leukemia and lymphocytosis treated with an anti-CD20 monoclonal antibody (IDEC-C2B8), rituximab. Ann Hematol, 77:89-91.

Kalpadakis C, Pangalis GA, Dimopoulou MN, et al. 2007. Rituximab monotherapy is highly effective in splenic marginal zone lymphoma. Hematol Oncol, 25:127-31.

Kaplan LD, Lee JY, Ambinder RF, et al. 2005. Rituximab does not improve clinical outcome in a randomized phase 3 trial of $\mathrm{CHOP}$ with or without rituximab in patients with HIV-associated non-Hodgkin lymphoma: AIDS-Malignancies Consortium Trial 010. Blood, 106:1538-43.

Kay NE, Geyer SM, Call TG, et al. 2007. Combination chemoimmunotherapy with pentostatin, cyclophosphamide, and rituximab shows significant clinical activity with low accompanying toxicity in previously untreated B chronic lymphocytic leukemia. Blood, 109:405-11.

Keating MJ, O'Brien S, Albitar M, et al. 2005. Early results of a chemoimmunotherapy regimen of fludarabine, cyclophosphamide, and rituximab as initial therapy for chronic lymphocytic leukemia. $J$ Clin Oncol, 23:4079-88. 
Kewalramani T, Zelenetz AD, Nimer SD, et al. 2004. Rituximab and ICE as second-line therapy before autologous stem cell transplantation for relapsed or primary refractory diffuse large B-cell lymphoma. Blood, 103:3684-3.

Kohler G, Milstein C. 1975. Continuous cultures of fused cells secreting antibody of predefined specificity. Nature, 256:495-7.

Lauria F, Lenoci M, Annino L, et al. 2001. Efficacy of anti-CD20 monoclonal antibodies (Mabthera) in patients with progressed hairy cell leukemia. Haematologica, 86:1046-50.

Lemieux B, Bouafia F, Thieblemont C, et al. 2004. Second treatment with rituximab in B-cell non-Hodgkin's lymphoma: efficacy and toxicity on 41 patients treated at CHU-Lyon Sud. Hematol J, 5:467-71.

Lenz G, Dreyling M, Hoster E, et al. 2005. Immunochemotherapy with rituximab and cyclophosphamide, doxorubicin, vincristine, and prednisone significantly improves response and time to treatment failure, but not long-term outcome in patients with previously untreated mantle cell lymphoma: results of a prospective randomized trial of the German Low Grade Lymphoma Study Group (GLSG). J Clin Oncol, 23:1984-92.

Leonard JP, Coleman M, Ketas JC, et al. 2003. Phase I/II trial of epratuzumab (humanized anti-CD22 antibody) in indolent non-Hodgkin's lymphoma. J Clin Oncol, 21:3051-9.

Leonard JP, Coleman M, Ketas JC, et al. 2004. Epratuzumab, a humanized anti-CD22 antibody, in aggressive non-Hodgkin's lymphoma: phase I/II clinical trial results. Clin Cancer Res, 10:5327-34.

Magni M, Di Nicola M, Devizzi L, et al. 2000. Successful in vivo purging of CD34-containing peripheral blood harvests in mantle cell and indolent lymphoma: evidence for a role of both chemotherapy and rituximab infusion. Blood, 96:864-9.

Maloney DG, Brown S, Czerwinski DK, et al. 1992. Monoclonal antiidiotype antibody therapy of B-cell lymphoma: the addition of a short course of chemotherapy does not interfere with the antitumor effect nor prevent the emergence of idiotype-negative variant cells. Blood, $80: 1502-10$

Maloney DG, Liles TM, Czerwinski DK, et al. 1994. Phase I clinical trial using escalating single-dose infusion of chimeric anti-CD20 monoclonal antibody (IDEC-C2B8) in patients with recurrent B-cell lymphoma. Blood, 84:2457-66.

Marcus R, Imrie K, Belch A, et al. 2005. CVP chemotherapy plus rituximab compared with CVP as first-line treatment for advanced follicular lymphoma. Blood, 105:1417-23.

Marcus RE, Solal-Celigny P, Imrie K, et al. 2006. MabThera (rituximab) plus cyclophosphamide, vincristine and prednisone (cvp) chemotherapy improves survival in previously untreated patients with advanced follicular non-Hodgkin's lymphoma (NHL). ASH Annual Meeting Abstracts, 108:481.

Martinelli G, Laszlo D, Ferreri AJM, et al. 2005. Clinical activity of rituximab in gastric marginal zone non-Hodgkin's lymphoma resistant to or not eligible for anti-Helicobacter pylori therapy. J Clin Oncol, 23:1979-83.

Matsui W, Huff CA, Wang Q, et al. 2004. Characterization of clonogenic multiple myeloma cells. Blood, 103:2332-6.

Matteucci P, Magni M, Di NM, et al. 2002. Leukoencephalopathy and papovavirus infection after treatment with chemotherapy and anti-CD20 monoclonal antibody. Blood, 100:1104-5.

McLaughlin P, Grillo-Lopez AJ, Link BK, et al. 1998b. Rituximab chimeric anti-CD20 monoclonal antibody therapy for relapsed indolent lymphoma: half of patients respond to a four-dose treatment program. J Clin Oncol, 16:2825-33.

Mele A, PulsoniA, Bianco E, et al. 2003. Hepatitis C virus and B-cell non-Hodgkin lymphomas: an Italian multicenter case-control study. Blood, 102:996-9.

Micallef IN, Maurer MJ, Nikcevich DA, et al. 2008. A phase II study of epratzumumab and rituximab in combination with cyclophosphamide, doxorubicin, vincristine and prednisone chemotherapy (ER-CHOP) in patients with previously untreated diffuse large B-cell lymphoma, p. abstr. 8500
Moreau P, Voillat L, Benboukher L, et al. 2007. Rituximab in CD20 positive multiple myeloma. Leukemia, 21:835-6.

Morgner A, Schmelz R, Thiede C, et al. 2007. Therapy of gastric mucosa associated lymphoid tissue lymphoma. World J Gastroenterol, 13:3554-66.

Mounier N, Briere J, Gisselbrecht C, et al. 2006. and Groupe d'Etude des Lymphomes de l'Adulte. Estimating the impact of rituximab on bcl-2-associated resistance to CHOP in elderly patients with diffuse large B-cell lymphoma. Haematologica, 91:715-6.

Mounier N, Briere J, Gisselbrecht C, et al. 2003. Rituximab plus CHOP (R-CHOP) overcomes bcl-2--associated resistance to chemotherapy in elderly patients with diffuse large B-cell lymphoma (DLBCL). Blood, 101:4279-84.

Mounier N, Spina M, Gisselbrecht C. 2007. Modern management of non-Hodgkin lymphoma in HIV-infected patients. Br J Haematol, 136:685-98.

Nadler LM, Stashenko P, Hardy R, et al. 1980. Serotherapy of a patient with a monoclonal antibody directed against a human lymphoma-associated antigen. Cancer Res, 40:3147-54.

Nieva J, Bethel K, Saven A. 2003. Phase 2 study of rituximab in the treatment of cladribine-failed patients with hairy cell leukemia. Blood, 102:810-3.

Nuckel H, Meller D, Steuhl KP, et al. 2004. Anti-CD20 monoclonal antibody therapy in relapsed MALT lymphoma of the conjunctiva. Eur J Haematol, 73:258-62.

O'Brien SM, Kantarjian H, Thomas DA, et al. 2001. Rituximab dose-escalation trial in chronic lymphocytic leukemia. J Clin Oncol, 19:2165-70.

Owen RG, Treon SP, Al-Katib A, et al. 2003. Clinicopathological definition of Waldenstrom's macroglobulinemia: consensus panel recommendations from the Second International Workshop on Waldenstrom's Macroglobulinemia. Semin Oncol, 30:110-5.

Ozgonenel B, Moonka D, Savasan S. 2006. Fulminant hepatitis B following rituximab therapy in a patient with Evans syndrome and large B-cell lymphoma. Am J Hematol, 81:302.

Perceau G, Diris N, Estines O, et al. 2006. Late lethal hepatitis B virus reactivation after rituximab treatment of low-grade cutaneous B-cell lymphoma. Br J Dermatol, 155:1053-6.

Pfreundschuh M, Ho AD, Cavallin-Stahl E, et al. 2008a. Prognostic significance of maximum tumour (bulk) diameter in young patients with goodprognosis diffuse large-B-cell lymphoma treated with CHOP-like chemotherapy with or without rituximab: an exploratory analysis of the MabThera International Trial Group (MInT) study. Lancet Oncol, 9:435-44

Pfreundschuh M, Schubert J, Ziepert M, et al. 2008b. Six versus eight cycles of bi-weekly CHOP-14 with or without rituximab in elderly patients with aggressive $\mathrm{CD} 20+\mathrm{B}$-cell lymphomas: a randomised controlled trial (RICOVER-60). Lancet Oncol, 9:105-16.

Pfreundschuh M, Trumper L, Osterborg A, et al. 2006. CHOP-like chemotherapy plus rituximab versus CHOP-like chemotherapy alone in young patients with good-prognosis diffuse large-B-cell lymphoma: a randomised controlled trial by the MabThera International Trial (MInT. Group). Lancet Oncol, 7:379-91.

Pfreundschuh M, Zeynalova S, Poeschel V, et al. 2007. Dose-dense rituximab improves outcome of elderly patients with poor-prognosis diffuse large B-cell lymphoma (DLBCL): results of the DENSE-R-CHOP-14 Trial of the German High-Grade Non-Hodgkin Lymphoma Study Group (DSHNHL). ASH Annual Meeting Abstracts, 110:789.

Philip T, Guglielmi C, Hagenbeek A, et al. 1995. Autologous bone marrow transplantation as compared with salvage chemotherapy in relapses of chemotherapy-sensitive non-Hodgkin's lymphoma. $N$ Engl J Med, 333:1540-5.

Pilarski LM, Hipperson G, Seeberger K, et al. 2000. Myeloma progenitors in the blood of patients with aggressive or minimal disease: engraftment and self-renewal of primary human myeloma in the bone marrow of NOD SCID mice. Blood, 95:1056-65.

Pileri S, Sabattini E, Poggi S, et al. 1994. Bone-marrow biopsy in hairy cell leukaemia (HCL) patients. Histological and immunohistological analysis of 46 cases treated with different therapies. Leuk Lymphoma, 14(Suppl 1):67-71. 
Piro LD, Carrera CJ, Carson DA, et al. 1990. Lasting remissions in hairy-cell leukemia induced by a single infusion of 2-chlorodeoxyadenosine. N Engl J Med, 19:1117-21.

Press OW, Appelbaum F, LedbetterJA, et al. 1987. Monoclonal antibody 1F5 (anti-CD20) serotherapy of human B cell lymphomas. Blood, 69:584-91.

Rai KR, Davey F, Peterson B, et al. 1995. Recombinant alpha-2b-interferon in therapy of previously untreated hairy cell leukemia: long-term follow-up results of study by Cancer and Leukemia Group B. Leukemia, 9:1116-20.

Ravandi F, Jorgensen JL, O’Brien SM, et al. 2006. Eradication of minimal residual disease in hairy cell leukemia. Blood, 107:4658-62.

Riley JK, Sliwkowski MX. 2000. CD20: a gene in search of a function, p. 17-24.

Robak T, Smolewski P, Cebula B, et al. 2007. Rituximab plus cladribine with or without cyclophosphamide in patients with relapsed or refractory chronic lymphocytic leukemia. Eur J Haematol, 79:107-13.

Robillard N, vet-Loiseau H, Garand R, et al. 2003. CD20 is associated with a small mature plasma cell morphology and $\mathrm{t}(11-14)$ in multiple myeloma. Blood, 102:1070-1.

Romaguera JE, Fayad L, Rodriguez MA, et al. 2005. High rate of durable remissions after treatment of newly diagnosed aggressive mantlecell lymphoma with rituximab plus hyper-CVAD alternating with rituximab plus high-dose methotrexate and cytarabine. J Clin Oncol, 23:7013-23.

Rottenburger C, Kiel K, Bosing T, et al. 1999. Clonotypic CD20+ and $\mathrm{CD} 19+\mathrm{B}$ cells in peripheral blood of patients with multiple myeloma post high-dose therapy and peripheral blood stem cell transplantation. Br J Haematol, 106:545-52.

Rubenstein JL, Fridlyand J, Abrey L, et al. 2007. Phase I study of intraventricular administration of rituximab in patients with recurrent CNS and intraocular lymphoma. J Clin Oncol, 25:1350-6.

Rule S, Burton C, Ross M. 2005. Combination with or without Rituximab in patients with untreatd mantle cell lymphoma.

Rummel MJ, Al-Batran SE, Kim SZ, et al. 2005. Bendamustine plus rituximab is effective and has a favorable toxicity profile in the treatment of mantle cell and low-grade non-Hodgkin's lymphoma. J Clin Oncol, 23:3383-9.

Salles GA, Foussard C, Nicolas M, et al. 2004. Rituximab added \{alpha\}IFN+CHVP improves the outcome of follicular lymphoma patients with a high tumor burden: to first analysis of the GELAGOELAMS FL-2000 randomized trial in 359 patients. ASH Annual Meeting Abstracts, 104:160.

Salles GA, Mounier N, de Guibert S, et al. 2007. Rituximab combined with chemotherapy and interferon in follicular lymphoma patients: final Analysis of the GELA-GOELAMS FL2000 study with a 5-year follow-up. ASH Annual Meeting Abstracts, 110:792.

Schulz H, Pels H, Schmidt-Wolf I, et al. 2004. Intraventricular treatment of relapsed central nervous system lymphoma with the anti-CD20 antibody rituximab. Haematologica, 89:753-54.

Shah GD, Yahalom J, Correa DD, et al. 2007. Combined immunochemotherapy with reduced whole-brain radiotherapy for newly diagnosed primary CNS lymphoma. J Clin Oncol, 25:4730-5.

Sieniawski M, Staak O, Glossmann JP, et al. 2007. Rituximab added to an intensified salvage chemotherapy program followed by autologous stem cell transplantation improved the outcome in relapsed and refractory aggressive non-Hodgkin lymphoma. Ann Hematol, 86:107-15.

Smith MR. 2003. Rituximab (monoclonal anti-CD20 antibody): mechanisms of action and resistance. Oncogene, 22:7359-68.

Sparano JA. 2007. HIV-associated lymphoma: the evidence for treating aggressively but with caution. Curr Opin Oncol, 19:458-63.

Spiers A, Moore D, Cassileth P. 1987. Pemissions in hairy cell leukemia with pentostatin (2`deoxycoformycin). $N$ Engl J Med, 316:825-30.

Stockmeyer B, Dechant M, van Egmond M, et al. 2000. Triggering FC $\{$ alpha $\}$-receptor I (CD89) recruits neutrophils as effector cells for CD20-directed antibody therapy. J Immunol, 165:5954-61.
Tam CS, O'Brien S, Wierda W, et al. 2008. Long-term results of the fludarabine, cyclophosphamide, and rituximab regimen as initial therapy of chronic lymphocytic leukemia. Blood, 112:975-80.

Tarella C, Zanni M, Magni M, et al. 2008. Rituximab improves the efficacy of high-dose chemotherapy with autograft for high-risk follicular and diffuse large B-cell lymphoma: a multicenter Gruppo Italiano Terapie Innnovative nei linfomi survey. $J$ Clin Oncol, 26:3166-75

Thieblemont C, Felman P, Berger F, et al. 2002. Treatment of splenic marginal zone B-cell lymphoma: an analysis of 81 patients. Clin Lymphoma, 3:41-7.

Thieblemont C, Felman P, Callet-Bauchu E, et al. 2003. Splenic marginal-zone lymphoma: a distinct clinical and pathological entity. Lancet Oncol, 4:95-103.

Thomas DA, Faderl S, O'Brien S, et al. 2006. Chemoimmunotherapy with hyper-CVAD plus rituximab for the treatment of adult Burkitt and Burkitt-type lymphoma or acute lymphoblastic leukemia. Cancer, 106:1569-80.

Thomas DA, O'Brien S, Bueso-Ramos C, et al. 2003. Rituximab in relapsed or refractory hairy cell leukemia. Blood, 102:3906-11.

Treon SP, Agus DB, Link B, et al. 2001. CD20-directed antibody-mediated immunotherapy induces responses and facilitates hematologic recovery in patients with Waldenstrom's macroglobulinemia. J Immunother, 24:272-9.

Treon SP, Emmanouilides C, Kimby E, et al. 2005. Extended rituximab therapy in Waldenstrom's macroglobulinemia. Ann Oncol, $16: 132-8$.

Treon SP, Pilarski LM, Belch AR, et al. 2002. CD20-directed serotherapy in patients with multiple myeloma: biologic considerations and therapeutic applications. J Immunother, 25:72-81.

Tsutsumi Y, Kanamori H, Mori A, et al. 2005. Reactivation of hepatitis B virus with rituximab. Expert Opin Drug Saf, 4:599-608.

van Oers MH, Klasa R, Marcus RE, et al. 2006b. Rituximab maintenance improves clinical outcome of relapsed/resistant follicular nonHodgkin's lymphoma, both in patients with and without rituximab during induction: results of a prospective randomized phase III intergroup trial. Blood, 108:3295-301.

Vose JM, Link BK, Grossbard ML, et al. 2001. Phase II study of rituximab in combination with chop chemotherapy in patients with previously untreated, aggressive non-Hodgkin's lymphoma. J Clin Oncol, 19:389-97.

Wierda W, O'Brien S, Wen S, et al. 2005. Chemoimmunotherapy with fludarabine, cyclophosphamide, and rituximab for relapsed and refractory chronic lymphocytic leukemia. J Clin Oncol, 23:4070-8.

Wong ET. 2005. Management of central nervous system lymphomas using monoclonal antibodies: challenges and opportunities. Clin Cancer Res, 11:77151s-7.

Wotherspoon AC, Ortiz-Hidalgo C, Falzon MR, et al. 1991a. Helicobacter pylori-associated gastritis and primary B-cell gastric lymphoma. Lancet, 338:1175-6.

Yamanaka R, Morii K, Shinbo Y, et al. 2008. Results of treatment of 112 cases of primary CNS lymphoma. Jpn J Clin Oncol, 38:373-80.

Yang H, Rosove MH, Figlin RA. 1999. Tumor lysis syndrome occurring after the administration of rituximab in lymphoproliferative disorders: highgrade non-Hodgkin's lymphoma and chronic lymphocytic leukemia. Am J Hematol, 62:247-50.

Zinzani PL, Alinari L, Stefoni V, et al. 2005. Rituximab in primary conjunctiva lymphoma. Leuk Res, 29:107-8.

Zinzani PL, Pulsoni A, Perrotti A, et al. 2004. Fludarabine plus mitoxantrone with and without rituximab versus $\mathrm{CHOP}$ with and without rituximab as front-line treatment for patients with follicular lymphoma. J Clin Oncol, 22:2654-61. 
